\title{
Neo-costumbrismo y polifonía literaria en Kartápolis
}

\section{Neo-costumbrismo and polyphony literary in Kartápolis}

\section{Neo-costumbrismo e polifonia literária em Kartápolis}

\author{
Jesús Camarero
}

Catedrático de Crítica Literaria, Literatura Comparada y Literatura francesa. Departamento de Filología Francesa Facultad de Letras. Universidad del País Vasco UPV/EHU. Po de la Universidad, 5. E-01006

Vitoria-Gasteiz/ Álava-Araba (España)

Cómo citar esta reseña en edición digital: Camarero, J. (2018). Neo-costumbrismo y polifonía literaria en Kartápolis. Cultura de los Cuidados (Edición digital), 22(50). Recuperado de http://dx.doi.org/10.14198/cuid.2018.50.21

Correspondencia: Remitirse al correo electrónico.

Correo electrónico: migueldue@gmail.com

Recibido: 012/03/2018; Aceptado: Reseña Invitada.

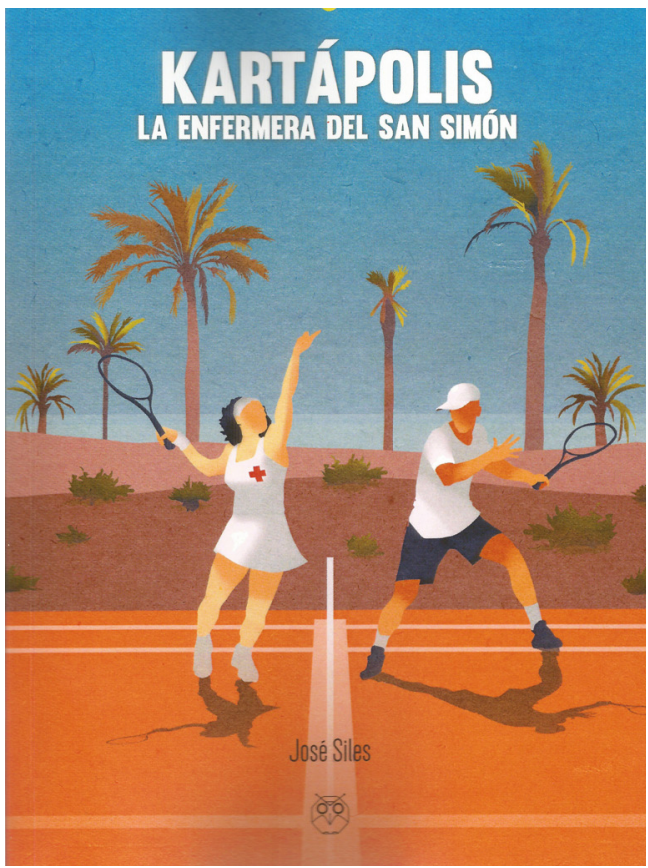

Figura 1: Portada de "Kartápolis. La enfermera del San Simón", novela de José Siles (2017).

Kartápolis. La Enfermera del San Simón/ Editorial Amarante. 404 páginas/ Fecha de publicación: 10/11/2017/ ISBN: 978-84947398-7-3

\section{ABSTRACT}

In this review, Dr. Camarero analyzes the narrative plot of a different novel: Kartápolis. Kartá- polis is a dense, abrupt, even overwhelming novel, certainly, but above all it is a polyphonic novel, in which the different voices of the characters are ordered successively, as if transported by a certain instantaneity of the narrative action. The author integrates the novel into neocostumbrismo (in the style of La Colmena de Cela) and the Valleinclanesco “esperpento". This novel by José Siles, Kartápolis, is a multifaceted and polyhedral narrative, in which the translation of a social reality, somewhat costumbrista, is supported and promoted by a modern, innovative polyphonic mechanism.

Keywords: novel, neo-costumbrismo and narrative, literary polyphony, Kartápolis.

\section{RESUMEN}

En esta reseña, el doctor Camarero analiza la trama narrativa de una novela diferente: Kartápolis. Kartápolis es una novela densa, abrupta, incluso arrolladora, ciertamente, pero sobre todo es una novela polifónica, en la que las distintas voces de los personajes están ordenadas de forma sucesiva, como transportadas por una cierta instantaneidad de la acción narrativa. El autor integra la novela dentro del neocostumbrismo (al estilo de La Colmena de Cela) y del esperpento Valleinclanesco. Esta novela de José Siles, Kartápolis, constituye una narración poliédrica y multificcional, en la que 
la traslación de una realidad social, un tanto costumbrista, se ve apoyada e impulsada por un mecanismo polifónico moderno, innovador.

Palabras clave: novela, neo-costumbrismo y narrativa, polifonía literaria, Kartápolis.

\section{RESUMO}

Nesta revisão, o Dr. Camarero analisa o enredo narrativo de um romance diferente: Kartápolis. Kartápolis é um romance denso, abrupto, até opressivo, certamente, mas acima de tudo é um romance polifônico, no qual as diferentes vozes dos personagens são ordenadas sucessivamente, como se transportadas por certa instantaneidade da ação narrativa. $\mathrm{O}$ autor integra o romance em neocostumbrismo (no estilo de La Colmena de Cela) e no Valleinclanesco grotesco. Este romance de José Siles, Kartápolis, é uma narrativa multifacetada e poliédrica, na qual a tradução de uma realidade social, um tanto costumbrista, é apoiada e promovida por um mecanismo polifônico moderno e inovador.

Palavras-chave: romance, neo-costumbrismo e narrativa, polifonia literária, Kartápolis.

La novela de José Siles, titulada Kartápolis. La enfermera del San Simón (Amarante, 2017), llega después de una larga trayectoria narrativa, en la que figunm Resaca Estigia (1987), La última noche de Erik Bicarbonato (1992), El hermeneuta insepulto (1993), La delirante travesía del soldador borracho y otros relatos (1995), El latigazo (1997), La venus de Donegal (2012) y La utopía reptante y o/ros relatos (2015); y también poética, con Protocolo del hastío (1996), El sentido del navegante (2001), La sal del tiempo (2006) y
Los tripulantes del Líricus (2014).

En cuanto al tema, en general, esta novela titulada Kartápolis habría que enmarcarla en la larga y exitosa tradición de la novela social -que no sociológica-, tan brillantemente representada por un tipo de relato como La colmena de Camilo José Cela. Y, dentro de ella, se la podría enmarcar a su vez en el costumbrismo que en cierto modo caracterizó la narrativa española en el siglo XIX, aunque en esta obra de algún modo se reinventa aquel costumbrismo adaptándolo a las formas y contenidos de una época muy distante de aquella, en pleno umbral del siglo XXI, o sea, estamos hablando de una especie de neocostumbrismo.

Para entender esta adscripción de Kartápolis al género costumbrista, creo que bastará una breve definición de Ramón de Mesonero Romanos, que caracteriza los cuadros del costumbrismo como "ligeros bosquejos o cuadros de caballete, ayudado de una acción dramática y sencilla, caracteres verosímiles y variados, y diálogo animado y castizo [ ... ] escribir para todos en estilo llano, sin afectación ni desaliño; pintar las más veces, razonar pocas, hacer llorar nunca, reír casi siempre".

En este libro de Siles, con un estilo situado a medio camino entre lo expositivo y satírico, aparecen descritas ciertas costumbres de nuestra sociedad, y quedan esbozados con trazo grueso los rasgos de la política y de la vida social de nuestra época. Dicho esto, se podría afirmar que Kartápolis da cuenta sobre todo de una intensa observación de la realidad, y es capaz de reflejar la vida de una época (la nuestra) y de un país (el nuestro), inmerso todavía en una fase de cns1s económicopolítica. Más concretamente, la defensa de unos valores a expensas de otros es algo que 
queda fielmente representado en la narración de Siles.

En la parte del dramatis personae, los personajes que protagonizan la novela siguen un modelo paródico, un tanto humorístico, como imitando quizá el ambiente de una ópera bufa, un vodevil o un café cantante, pero adaptado a las coordenadas de nuestra época, tan amante de la televisión comercial, o sea en plena civilización del espectáculo, como diría Mario Vargas Llosa. Por tanto la novela tiene un registro irónico y cómico innegable, acompañado -o mejor, trasladadopor un lenguaje popular, no chabacano, sino coloquial y directo, con las palabras comunes justas que permiten reconocerlo como tal y sin que ello llegue a afecta a su entidad literaria. Sin duda, la idea de un neo-costumbrismo contemporáneo se abre camino apoyada por esta tesis del lenguaje popular y la comicidad.

En este sentido, el autor, que está muy atento a las costumbres de la gente (más que a los movimientos de la masa o su evolución), profundiza en los gestos, palabras y acciones de cada personaje, para analizarlo todo con una actitud crítica, bien sea cuando se trata de la institución psiquiátrica del hospital San Simón, bien sea a propósito de la institución universitaria, por ejemplo. El resultado suele ser una visión ridiculizadora, relativista, incluso satírica de la sociedad, al modo del esperpento más típico de Valle-lnclán en Luces de bohemia, pero guarda siempre una pequeña distancia para obtener un margen de humanidad en todo caso.

Por otra parte, ello no impide que la narración nos sea trasladada generalmente desde una voz que adopta además un sesgo más o menos autobiográfico, aunque solo sea por la cercanía y la intimidad que desea provocar esa voz de tono amistoso y sincero, sin llegar a ser una auténtica confesión, porque en esto no sigue el estilo de Jean-Jacques Rousseau en sus Confesiones. Sin embargo, esa voz tiene en el lector un efecto de solidaridad comprensión, a veces ciertamente conmovedor. En realidad, para ser más exactos, se trata de un relato más bien auto-ficcional, porque el peso de la ficción inclina la balanza del lado de la imaginación, y no tanto de la memoria, la identidad o la existencia.

La verdad es que a José Siles no le duelen prendas al practicar una mezcla de lenguaje popular y erudito, que da una impresión intensa de instantaneidad y complejidad al mismo tiempo, y que, por su efectividad $y$ también su efectismo, recuerda un poco a la prosa de Francisco de Quevedo en aquellas páginas inolvidables e insuperables de La culta latiniparla, aunque sin los extremos verbales que rozan lo indecible en Quevedo. Sin duda, la literatura española actual tiene muy presente en sus textos el enorme legado de la lengua literaria del Siglo de Oro, por mucho que nuestra literatura sea ya tan moderna $\mathrm{y}$ tan vanguardista como cualquier otra. $\mathrm{Si}$ hay alguna duda sobre esto que acabo de decir, sirva de referencia en este caso la prosa cervantina, o cervantesca, de Andrés Trapiello, escritor tan moderno y tan clásico a la vez que nos descubre la modernidad histórica de esas épocas culminantes, como es el caso del Siglo de Oro. En esta misma línea cabría situar a Siles con sus páginas atiborradas de un discurso inundante y directo, ingenioso $y$ creativo, seductor y sorprendente.

En una primera impresión, esta novela de Siles podría considerarse próxima al realismo mágico del Macondo de Gabriel García Márquez. Pero no lo hace tanto por la configuración del mundo ficcional, sino más bien por su estilo alambicado, gustoso de una cierta plenitud 
verbal, repleto de objetos y detalles, en un ambiente urbano eso sí, de sensación cálida y ritmo acompasado. Así que, según esta primera impresión, se trata de una voluminosa novela, que a ratos parece complacerse en un sistema de pequeñas narraciones con gran vocación descriptivista que, tomadas en determinadas secuencias agrupadas, podría parecer que se suceden ordenadamente, por ejemplo, al modo de las variaciones musicales de Johann Sebastian Bach.

En realidad, Kartápolis es una novela densa, abrupta, incluso arrolladora, ciertamente, pero sobre todo es una novela polifónica, en la que las distintas voces de los personajes están ordenadas de forma sucesiva, como transportadas por una cierta instantaneidad de la acción narrativa. Lo que ocurre es que el narrador omnisciente llega a transmutarse, en esta novela, según dos niveles narrativos: por un lado, adopta por lo general el rol de una persona, dando al relato un aire homodiegético, autobiográfico, memorístico, aunque solo en apariencia; y por otro lado, adopta la personalidad de distintos actantes, sin ser ninguno de ellos en realidad.

Este fenómeno tiene además una traslación material y práctica al propio texto, en el que los capítulos se dividen en epígrafes, cada uno de ellos dedicado a un personaje. Como se puede fácilmente comprobar leyendo la novela, el autor tiene una gran capacidad para jugar con la realidad y la apariencia, sin duda debido a que los recursos de la ironía le permiten moverse en planos diferentes del relato.

La instancia discursiva en la que se sitúa el narrador cambia en cada uno de los tres capítulos de que consta la novela, y lo hace de un modo progresivo, provocando una apertura de su voz, desde la instancia más básica o próxima ( el yo de la $1^{\text {a }}$ ), luego hacia la instancia ajena en la que el yo se encuentra con el otro ( el tú de la $2^{\mathrm{a}}$ ), hasta llegar a la diseminación del resto de personas posibles (él, ella, de la

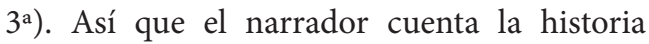
desde todos los puntos de vista d.1, todos los personajes: en el capítulo $1^{\circ}$ en !a persona, en el segundo en $2^{\mathrm{a}}$, y en el $3^{\circ}$ en $3^{\mathrm{a}}$ persona. Se trata por tanto de una polifonía variable $y$ multifocal, con efectos multifíccionales, ya que en cada caso el personaje relata los hechos a su modo, lo cual da lugar a historias diferentes, solo coincidentes en lo básico que permite relacionarlas con las demás.

Esta estructura narrativa polifónica de Kartápolis implica, como ya se ha dicho, la referencia sucesiva de los personajes a los mismos acontecimientos. Este mecanismo produce un efecto de simultaneidad de las acciones narrativas que, de este modo, son relatadas desde múltiples puntos de vista, todos diferentes, pero coincidentes. Quizá debido a esta técnica, la acción en su conjunto no avanza todo lo rápidamente que el lector quisiera, pero ese lector se entretiene -en ambos sentidos- en el juego fractal de distintos relatos con un solo referente, obteniendo una visión caleidoscópica que proporciona un abanico de posibilidades narrativas más o menos simétricas, como si fuera un juego interno y especular de la novela.

Esta estructura narrativa tan original de Kartápolis es en realidad una estructura formal literaria, un juego de las formas dentro de la obra, un sistema de construcción interna del relato (hiperconstrucción), es un recurso de la función poética del lenguaje literario (Roman Jakobson), Por consiguiente, en el acto de la lectura, el lector tiene que re-figurarse esa estructura organizada o compuesta en la obra por el autor, que la ha pre figurado en el acto de la escritura (Paul Ricoeur). 
El juego polifónico consiste, en definitiva, en descubrir virtualidades argumentales de la narración, porque, al contar historias diferentes relacionadas con un mismo acontecimiento, los personajes (el narrador transmutado) nos ofrecen detalles, acciones y tramas diferentes. Así que, de este modo, el narrador trata de agotar todas las posibilidades narrativas de su argumentario, ofreciendo al lector una visión caleidoscópica de los hechos narrados. Este tipo de narración es un hallazgo técnico de Siles, por el cual el lector se enfrenta a una novela-puzzle en la que muchas piezas tienen la misma forma por mucho que representen escenas distintas. La novela-puzzle es el resultado, entonces, del juego de las estructuras formales polifónicas y constituye, en mi opinión, un aspecto muy sobresaliente y llamativo de Kartápolis.

Además, este juego polifónico de la novela de Siles tiene también algunas implicaciones respecto del estilo. Las frases son rápidas, incluso aunque sean largas, debido a que la puntuación, un tanto especial, no impide una lectura ágil, incluso de ritmo acelerado en algunos párrafos. Este fenómeno tiene que ver con wla cuestión cuantitativa (la enorme cantidad de palabras que es capaz de generar su narrador) y con una cuestión cualitativa (un estilo rápido e inundante).

A este respecto, resulta conveniente hacer una anotación sobre la estrategia que debe seguir el lector, y que es también wla especie de recomendación, absolutamente amistosa: en esta novela de Siles, dadas sus características, y como ocurre también en otros autores como Marce! Proust, el lector tiene que dosificar correctamente su impulso lectura!, de modo que pueda hacerse con el control de la historia y sus entresijos, capturando todo lo depositado en el argumento sin excepción, y sin que la fatiga le impida disfrutar de todos los detalles previstos por el autor.

Esta novela, por tanto, no funciona igual que la novela tradicional, con un planteamiento, un nudo y un desenlace. Y también es verdad. que Kartápolis es una novela que no se desarrolla como muchas otras novelas que siguen el modelo clásico o tradicional. En Kartápolis, como ocurre también en muchas narraciones vanguardistas y postmodernas, por ejemplo, del tipo del Nouveau Roman francés de los años 1950, la estructura compositiva de la obra es completamente diferente, los personajes funcionan de otro modo, la trama no sigue un impulso lineal, la lógica narrativa no es la acostumbrada, el argumento ha sido desconstruido por medio de una estructura formal original, incluso el lenguaje no se corresponde con lo establecido en ciertos cánones academicistas.

En síntesis, esta novela de José Siles, Kartápolis, constituye una narración poliédrica y multificcional, en la que la traslación de una realidad social, un tanto costumbrista, se ve apoyada e impulsada por un mecanismo polifónico moderno, innovador. La densidad de este relato, a la que ya hemos aludido antes, quizá se debe a esto precisamente, al hecho de dar cabida en el discurso narrativo a este juego complejo que consiste en narrar unos hechos (que casi todos los lectores reconocerán enseguida) de un modo ciertamente diferente (con una estructura original y atractiva). 